American Journal of Environmental Sciences 4 (5): 502-511, 2008

ISSN 1553-345X

(C) 2008 Science Publications

\title{
Sulfur Recovery from Acid Gas Using the Claus Process and High Temperature Air Combustion (HiTAC) Technology
}

\author{
${ }^{1}$ Mohamed Sassi and ${ }^{2}$ Ashwani K. Gupta \\ ${ }^{1}$ Department of Chemical and Mechanical Engineering, \\ The Petroleum Institute, P.O. Box 2533, Abu Dhabi, UAE \\ ${ }^{2}$ Department of Mechanical Engineering, University of Maryland, \\ College Park, MD 20742, USA
}

\begin{abstract}
Sulfur-bearing compounds are very detrimental to the environment and to industrial process equipment. They are often obtained or formed as a by-product of separation and thermal processing of fuels containing sulfur, such as coal, crude oil and natural gas. The two sulfur compounds, which need special attention, are: hydrogen sulfide $\left(\mathrm{H}_{2} \mathrm{~S}\right)$ and sulfur dioxide $\left(\mathrm{SO}_{2}\right) . \mathrm{H}_{2} \mathrm{~S}$ is a highly corrosive gas with a foul smell. $\mathrm{SO}_{2}$ is a toxic gas responsible for acid rain formation and equipment corrosion. Various methods of reducing pollutants containing sulfur are described in this paper, with a focus on the modified Claus process, enhanced by the use of High Temperature Air Combustion (HiTAC) technology in the Claus furnace. The Claus process has been known and used in the industry for over 100 years. It involves thermal oxidation of hydrogen sulfide and its reaction with sulfur dioxide to form sulfur and water vapor. This process is equilibrium-limited and usually achieves efficiencies in the range of $94-97 \%$, which have been regarded as acceptable in the past years. Nowadays strict air pollution regulations regarding hydrogen sulfide and sulfur dioxide emissions call for nearly $100 \%$ efficiency, which can only be achieved with process modifications. High temperature air combustion technology or otherwise called flameless (or colorless) combustion is proposed here for application in Claus furnaces, especially those employing lean acid gas streams, which cannot be burned without the use of auxiliary fuel or oxygen enrichment under standard conditions. With the use of HiTAC it has been shown, however, that fuel-lean, Low Calorific Value (LCV) fuels can be burned with very uniform thermal fields without the need for fuel enrichment or oxygen addition. The uniform temperature distribution favors clean and efficient burning with an additional advantage of significant reduction of NOx, $\mathrm{CO}$ and hydrocarbon emission.
\end{abstract}

Key words: Sulfur recovery, acid gas, Claus process, flameless or colorless combustion

\section{INTRODUCTION}

Hydrogen sulfide is present in numerous gaseous waste streams from natural gas plants, oil refineries, wastewater treatment, among other processes. These streams usually also contain carbon dioxide, watervapor, trace quantities of hydrocarbons, sulfur and ammonia. Waste gases with ammonia are called sour gases, while those without ammonia are called acid gases. Sulfur must be recovered from these waste streams before flaring them.

Sulfur recovery from sour or acid gas typically involves application of the famous Claus process ${ }^{[1]}$ using the reaction between hydrogen sulfide and sulfur dioxide (produced in the Claus process furnace from the combustion of $\mathrm{H}_{2} \mathrm{~S}$ with air and/or oxygen) yielding elemental sulfur and water vapor:

$$
2 \mathrm{H}_{2} \mathrm{~S}(\mathrm{~g})+\mathrm{SO}_{2}(\mathrm{~g}) \rightarrow(3 / \mathrm{n}) \mathrm{S}_{\mathrm{n}}(\mathrm{g})+2 \mathrm{H}_{2} \mathrm{O}(\mathrm{g})
$$

with

$$
\Delta \mathrm{H}_{\mathrm{r}}=-108 \mathrm{~kJ} \mathrm{moL}^{-1}
$$

Therefore, higher conversions for this exothermic, equilibrium-limited reaction call for low temperatures which lead to low reaction rates, imposing the use of a catalyst. The catalytic conversion is usually carried out in a multi-stage fixed-bed adsorptive reactors process, to counteract the severe equilibrium limitations at high conversions. This technology process can possibly provide about $96-97 \%$ conversion of the influent sulfur in $\mathrm{H}_{2} \mathrm{~S}$ to $\mathrm{S}$. However, higher removal requires critical examination of the process and use of near isothermal reactor since the conversion is critically dependent

Corresponding Author: Mohamed Sassi, Department of Chemical and Mechanical Engineering, The Petroleum Institute, P.O. Box 2533, Abu Dhabi, UAE 
upon exothermic and endothermic conditions of the reactions. Flameless combustion has been shown to provide uniform thermal field in the reactor so that the reactor temperature is near uniform ${ }^{[2,3,4]}$. In addition it has been shown to result in compact size of the reactor, reduce combustion generated pollutants emission up to $50 \%$ and increase energy efficiency up to $30 \%{ }^{[5]}$. The application of this technology appears to offer great advantages for the process under consideration.

The UAE, which pumps about 2.4 million bpd of crude oil, is also home of the world's fifth biggest gas reserves at about 200 trillion cubic feet. Abu Dhabi Gas Industries (GASCO), an operating company of the $\mathrm{Abu}$ Dhabi National Oil Company (ADNOC), is leading a drive to boost gas production in the UAE from five to seven billion cubic feet per day. This calls for sulfur recovery capacity of over 3000 metric tons per day with the associated $\mathrm{SO}_{\mathrm{x}}$ and $\mathrm{NO}_{\mathrm{x}}$ emissions. Therefore, the adoption and further development of flameless combustion technology for sulfur recovery among other commercial and industrial heating processes is expected to be very crucial and beneficial, both economically and environmentally.

The conventional Sulfur recovery process is based upon the withdrawal of sulfur by in-situ condensation within the reactor. The selective removal of water should, however, be a far more effective technique as its effect on the equilibrium composition in the mass action equation is much greater. The in-situ combination of the heterogeneously catalyzed Claus reaction and an adsorptive water separation seems especially promising, as both reaction and adsorption exhibit similar kinetics and pressure can be adapted to the needs of the adsorptive separation. Such an adsorptive reactor will lead to almost complete conversion as long as the adsorption capacity is not exhausted. There are numerous possibilities for implementing these two functionalities, ranging from fixed-beds with homogeneous catalyst/adsorbent mixtures to spatially structured distributions or even fluidized beds.

For the sulfur recovery process most of the previous studies have concentrated on the Claus catalytic conversion reactors and the Tail Gas Treatment Unit TGTU ${ }^{[6]}$. However, some previous studies have identified the Claus furnace as one of the most important yet least understood parts of the modified Claus process ${ }^{[7]}$. The furnace is where the combustion reaction and the initial sulfur conversion (through an endothermic gaseous reaction) take place and also where the $\mathrm{SO}_{2}$ required by the downstream catalytic stages is produced and the contaminants (such as ammonia and BTX (benzene, toluene, xylene) are supposedly destroyed. The main two reactions in the Claus furnace are:

with

$$
\mathrm{H}_{2} \mathrm{~S}+3 / 2 \mathrm{O}_{2} \rightarrow \mathrm{SO}_{2}+\mathrm{H}_{2} \mathrm{O}
$$

$$
\Delta \mathrm{H}_{\mathrm{r}}=-518 \mathrm{~kJ} \mathrm{moL}^{-1}
$$$$
2 \mathrm{H}_{2} \mathrm{~S}+\mathrm{SO}_{2} \rightarrow 3 / 2 \mathrm{~S}_{2}+2 \mathrm{H}_{2} \mathrm{O}
$$

with

$$
\Delta \mathrm{H}_{\mathrm{r}}=+47 \mathrm{~kJ} \mathrm{moL}^{-1}
$$

This last endothermic reaction is responsible for up to $67 \%$ conversion of the sulfur at about $1200^{\circ} \mathrm{C}$. Moreover, many side reactions take place in the furnace, which reduce sulfur recovery and/or produce unwanted components that end up as ambient pollutant emissions. Therefore, it would be useful to combine the endothermic and exothermic process using an isothermal reactor offered by the flameless (or colorless) oxidation combustion.

A vast majority (about 92\%) of the 8 million metric tons of sulfur produced in the United States in 2005 was recovered from industrial by-products using the Claus process ${ }^{[8]}$. However, the traditional Claus process does face limitations and various process improvements have been investigated in order to satisfy the increasingly stringent emission regulations and the need to process gas streams and fuels with higher sulfur content. New technologies have to be developed in order to achieve $100 \%$ removal of sulfur compounds from industrial flue gases. The Claus process and its various derivatives and improvements are described here for treatment of $\mathrm{H}_{2} \mathrm{~S}$ containing streams. The use of HiTAC technology as a reliable and cost-effective alternative for improvement of lean acid gas treatment in the Claus process is proposed and described. Finally, the flameless or colorless combustion is proposed and described for processing acid-rich gas.

The Traditional Sulfur Recovery Process: The three main steps of sulfur recovery from sour gas are described below.

Amine Extraction: Gas containing $\mathrm{H}_{2} \mathrm{~S}$ is passed through an absorber containing an amine solution (Monoethanolamine (MEA), Diethanolamine (DEA), Methyldiethanolamine (MDEA), Diisopropylamine (DIPA), or Diglycolamine (DGA)), where the hydrogen sulfide is absorbed along with carbon dioxide. A typical amine gas treating process, shown in Fig. 1, includes an absorber unit and a regenerator unit as well as 


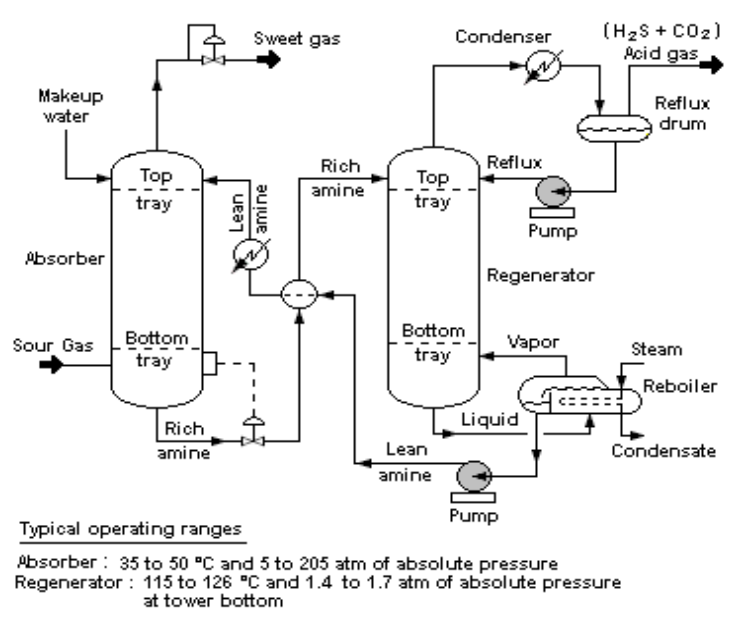

Fig. 1: Flow diagram of a typical amine treating process used in industrial plants ${ }^{[9]}$

accessory equipment ${ }^{[9]}$. In the absorber, the downflowing amine solution absorbs $\mathrm{H}_{2} \mathrm{~S}$ and $\mathrm{CO}_{2}$ (referred to as acid gases) from the up-flowing sour gas to produce a sweetened gas stream (i.e., an $\mathrm{H}_{2} \mathrm{~S}$-free gas) as a product and an amine solution rich in the absorbed acid gases. The resultant rich amine is then routed into the regenerator (a stripper with a re-boiler) to produce regenerated or lean amine that is recycled for reuse in the absorber. The stripped overhead gas from the regenerator is concentrated $\mathrm{H}_{2} \mathrm{~S}$ and $\mathrm{CO}_{2}$. The extracted mixture of $\mathrm{H}_{2} \mathrm{~S}$ and $\mathrm{CO}_{2}$, referred to as an acid gas, is passed into the Claus unit for sulfur recovery. The process is also known as Gas sweetening and Acid gas removal. Amines are also used in many oil refineries to remove acid gases from liquid hydrocarbons such as Liquefied Petroleum Gas (LPG).

Claus Thermal Stage: $\mathrm{H}_{2} \mathrm{~S}$ is partially oxidized with air (one-third of $\mathrm{H}_{2} \mathrm{~S}$ is converted into $\mathrm{SO}_{2}$ ) in the Claus furnace. The acid gas/air mixture is passed into a furnace operating at temperatures from 1300-1700 K, where the reactions are allowed sufficient time to reach equilibrium. The products from this step are: sulfur dioxide, water and unreacted hydrogen sulfide. Additionally some of the sulfur dioxide produced here reacts with hydrogen sulfide inside the furnace to produce sulfur according to reactions 1 and 2 shown earlier. The furnace products flow then into a waste heat boiler to condense the sulfur and produce high pressure steam for the Claus catalytic stages.

Depending on the calorific value of the acid gas, various methods of stable burning are achieved. If very lean acid gases are involved (low calorific value) then auxiliary fuel, oxygen enrichment or a by-pass stream has to be used. The $\mathrm{H}_{2} \mathrm{~S}$-content and the concentration of other combustible components (hydrocarbons or ammonia) determine the location where the feed gas is burned. Claus gases (acid gas) with no further combustible contents apart from $\mathrm{H}_{2} \mathrm{~S}$ are burned in lances surrounding a central muffle. Gases containing ammonia, such as the gas from the refinery's Sour Water Stripper (SWS) or hydrocarbons are converted in the burner muffle.

Claus Catalytic Stage: The remaining $\mathrm{H}_{2} \mathrm{~S}$, from the Claus furnace, is reacted with the $\mathrm{SO}_{2}$ at lower temperatures (about 470-620 K) over an alumina- or titanium dioxide-based catalyst to make more sulfur:

$$
\begin{gathered}
2 \mathrm{H}_{2} \mathrm{~S}+\mathrm{SO}_{2} \leftrightarrow 3 / 8 \mathrm{~S}_{8}+2 \mathrm{H}_{2} \mathrm{O} \\
\Delta \mathrm{H}_{\mathrm{r}}=-108 \mathrm{~kJ} \mathrm{moL}^{-1}
\end{gathered}
$$

On average, about $70 \%$ of $\mathrm{H}_{2} \mathrm{~S}$ and $\mathrm{SO}_{2}$ will react via reaction (3). Note that in the catalytic stage mostly $\mathrm{S}_{8}$ is produced, which is an exothermic reaction whereas in the thermal stage $S_{2}$ is the major product and the reaction is endothermic. Other allotropes of sulfur may also be present in smaller quantities.

The overall reaction for the entire process is:

$$
\begin{gathered}
3 \mathrm{H}_{2} \mathrm{~S}+1.5 \mathrm{O}_{2} \rightarrow 3 / \mathrm{nS}_{\mathrm{n}}+3 \mathrm{H}_{2} \mathrm{O} \\
\Delta \mathrm{H}_{\mathrm{r}}=-626 \mathrm{~kJ} \mathrm{moL}^{-1}
\end{gathered}
$$

Reactions 1 and 3 are exothermic and a cooling stage is needed following these steps in order to condense the sulfur produced. The condensed phase is then separated from the gas stream by draining it into a container. An interesting property of liquid sulfur is its increase in viscosity with temperature ${ }^{[1]}$. This is due to polymerization of sulfur at around $430 \mathrm{~K}$. Therefore, the temperature of condensed sulfur should be closely monitored to prevent polymerization and clogging of pipes used in the process. Care must also be taken in order not to pass condensed sulfur through the catalyst, which would become fouled and inefficient. Liquid sulfur adsorbs to the pores and deactivates the catalytic surface. Therefore reheat stages using the previously generated steam are needed in order to keep the sulfur in gas phase while in the catalytic stage. Several methods of reheating used in industry are: 


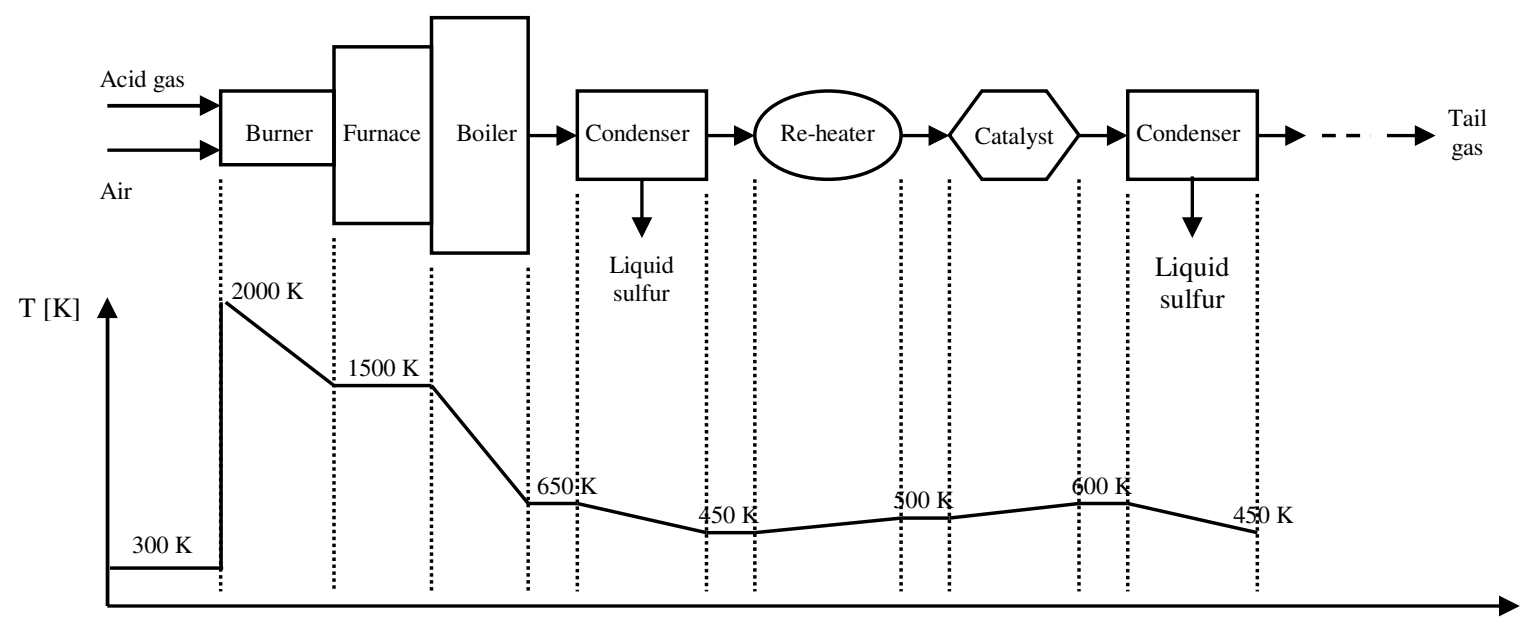

Fig. 2: Flow diagram of a typical Claus process

Hot-Gas Bypass: involves mixing the two process gas streams from the process gas cooler (cold gas) and the bypass (hot gas) from the first pass of the waste heat boiler.

Indirect Steam Reheaters: the gas can also be heated with high pressure steam in a heat exchanger.

Gas/Gas Exchangers: whereby the cooled gas from the process gas cooler is indirectly heated from the hot gas coming out of an upstream catalytic reactor in a gas-to-gas exchanger.

Direct-fired Heaters: fired reheaters utilizing acid gas or fuel gas, which is burned substoichiometrically to avoid oxygen breakthrough and damage to Claus catalyst.

A typical Claus process involves one thermal stage followed by multiple catalytic stages in series to maximize efficiency. The need for multiple catalytic stages increases complexity and cost. Therefore, various methods of minimizing these steps in the process have been proposed.

A schematic of the process flow diagram along with approximate gas temperatures is shown in Fig. 2. High-pressure steam (40 atm) is generated in the boiler stage and low-pressure steam (3-4 atm) is produced in the condensers. A total of two to four catalytic stages are typically used in order to maximize efficiency. The tail gas is either routed to a clean-up unit or to a thermal oxidizer to incinerate the remaining sulfur compounds into $\mathrm{SO}_{2}$. Where an incineration or tail-gas treatment unit (TGTU) is added downstream of the Claus plant, only two catalytic stages are usually installed. Before storage and downstream processing, liquid sulfur streams from the process gas cooler, the sulfur condensers and from the final sulfur separator are routed to the degassing unit, where the gases (primarily $\mathrm{H}_{2} \mathrm{~S}$ ) dissolved in the sulfur are removed. Over 2.6 tons of steam will be generated for each ton of sulfur yield.

The Claus process is equilibrium-limited. In the furnace stage the $\mathrm{SO}_{2}$ produced from the combustion process (reaction 1) recombines with $\mathrm{H}_{2} \mathrm{~S}$ in an endothermic reaction to form $S_{2}$ (reaction 2). Adequate residence time has to be provided in order to allow this reaction, responsible for $60-70 \%$ of sulfur conversion, to reach equilibrium ${ }^{[10]}$. Since the main Claus reaction 3 is exothermic, this stage calls for the use of low temperatures in order to shift the equilibrium constant towards higher product yields. The low temperatures, however, lead to decreased reaction rates, hence the need for a catalyst. The law of mass action for the Claus reaction is as follows:

$$
\mathrm{K}_{\mathrm{p}}(\mathrm{T})=\frac{\mathrm{p}_{\mathrm{H}_{2} \mathrm{O}}^{2} \mathrm{p}^{3 / 8} \mathrm{~S}_{8}}{\mathrm{p}^{2}{ }_{\mathrm{H}_{2}} \mathrm{~S}_{\mathrm{SO}_{2}}}
$$

Where, $K_{p}(T)$ is the chemical equilibrium constant and $\mathrm{p}_{\mathrm{H} 2 \mathrm{O}}, \mathrm{p}_{\mathrm{S} 8}$ are partial pressures of the products and $\mathrm{p}_{\mathrm{H} 2 \mathrm{~S}}, \mathrm{p}_{\mathrm{SO} 2}$ and partial pressures of the reactants.

This equation illustrates the nature of equilibrium limitations involved in the Claus process; decreasing the process temperature can increase the equilibrium constant and thus increase conversion, but the lower limit of this temperature and hence the upper limit of equilibrium conversion is set by the condensation temperature of sulfur. A typical arrangement for the Claus sulfur recovery process is shown in Fig. 3. 


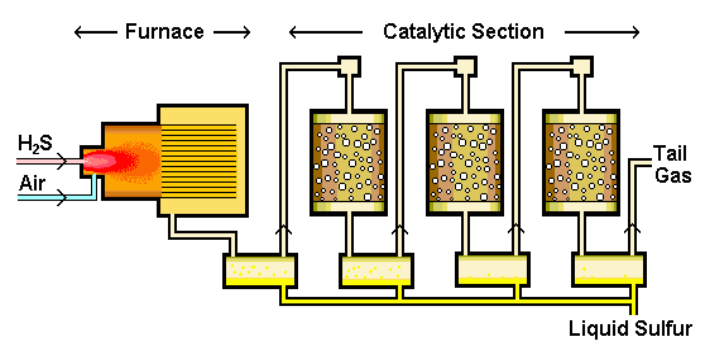

Fig. 3: Typical arrangement of a Claus unit ${ }^{[11]}$

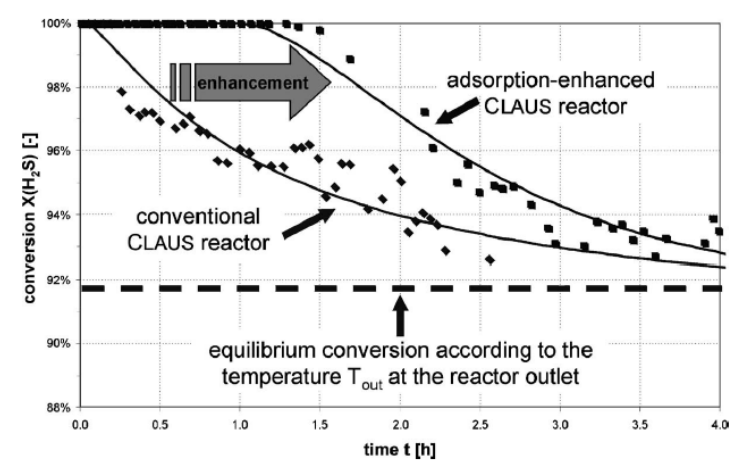

Fig. 4: Hydrogen sulfide conversion as a function of time ${ }^{[6]}$

Improvements on Claus Process: The traditional Claus process has been a reliable and relatively efficient way of removing hydrogen sulfide from the flue gas and converting it into elemental sulfur. It has, however, faced some shortcomings and limitations. Increasingly stringent air pollution regulations from oil, gas and chemical processing facilities combined with the fact that lower-grade, higher sulfur-content fuels will have to be used in the near future, call for improved efficiency of the process.

Elsner, et $a l_{.}^{[6]}$ proposed an adsorptive water separation process applied in the catalytic reactor stage. Taking advantage of Le Chatelier's principle, this process removes $\mathrm{H}_{2} \mathrm{O}$ (one of the products) from the reaction, shifting equilibrium towards higher conversion (Eq. 5). An adsorptive reactor of this type could produce complete conversion in a single catalytic stage.

The Zeolite adsorbent beads saturate with water after a certain time and therefore need to be regenerated. This calls for a cyclic process where the flow of gas is reversed and hot gas is used to vaporize the adsorbed water off of the surface of Zeolite spheres and remove them from the reactor. The process can then be reversed again to regenerate the second adsorptive reactor (Fig. 4).

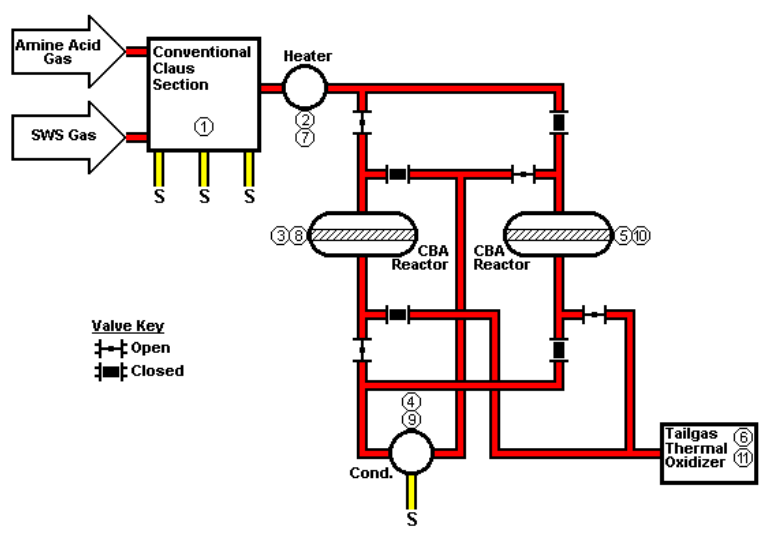

Fig. 5: Cold bed adsorption process diagram ${ }^{[12]}$

Figure 4 shows that $100 \%$ conversion can be achieved in the reactor for a longer time than in a conventional Claus reactor with no water adsorption. The decline in conversion efficiency after a period of about $1.3 \mathrm{hrs}$ is due to the fact that the Zeolite spheres are saturated with steam and they need to be regenerated. It was also found that as a side effect of the water adsorption, the chemisorption of $\mathrm{SO}_{2}$ on the surface of the alumina catalyst occurs.

A Cold Bed Adsorption (CBA) process, also known as the sub-dew point process developed by the Amoco Corporation has been shown to produce efficiencies in the range of $97.5-99.5 \%^{[12]}$. In the CBA process the heterogeneous catalytic reaction is allowed to take place at low temperatures (below sulfur dew point), thus increasing equilibrium conversion. Additionally since the Claus reaction occurs in the gas phase, this liquid sulfur does not inhibit the reaction like sulfur vapor does, effectively removing one of the reaction products to result in a favorable shift in the reaction equilibrium and higher sulfur conversion. The condensed phase is then periodically desorbed from the catalytic surface by flowing hot gas through the unit to vaporize the condensate, thus regenerating the reactor. Therefore, this process is inherently a cyclic one.

There are normally two or more CBA reactors in series so that at least one can be operating sub-dew point while the other is being regenerated, Fig. 5. Due to the cyclic nature of the CBA process, the CBA switching valves are subjected to very demanding sulfur vapor service that has caused significant operation and maintenance problems in many of the CBA plants designed by others. Sulfur recoveries in excess of $99.5 \%$ have been achieved with the Modified Claus process with tail gas cleanup developed by 
Am. J. Environ. Sci., 4 (5): 502-511, 2008

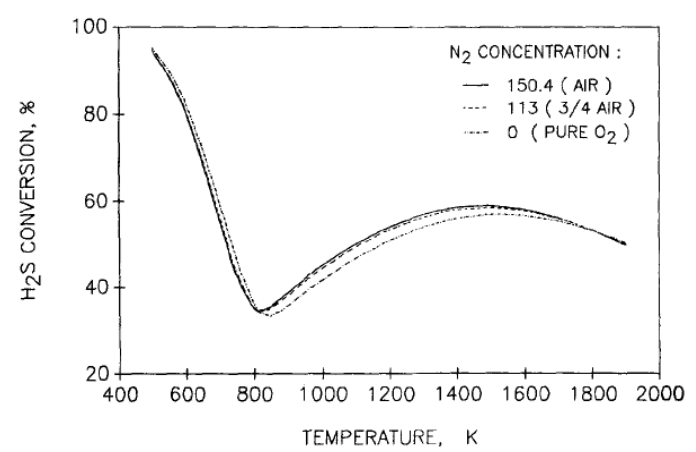

Fig. 6: Calculated hydrogen sulfide conversion as a function of reactor temperature for different oxygen concentrations ${ }^{[16]}$

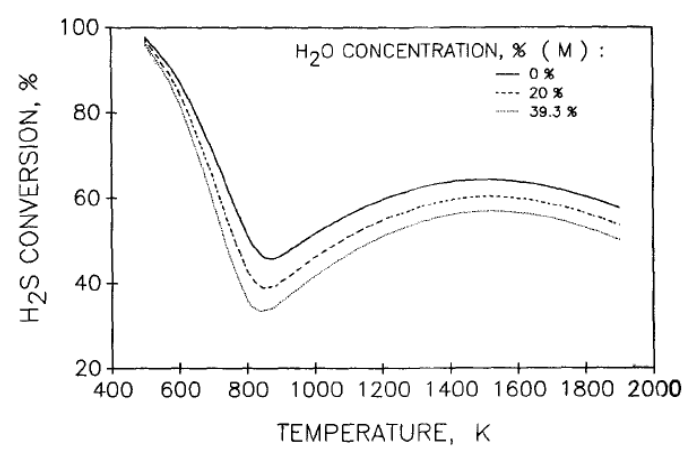

Fig. 7: Calculated hydrogen sulfide conversion as a function of reactor temperature for different water concentrations ${ }^{[16]}$

Ortloff $^{[13]}$. In this process the sulfur-bearing compounds (COS, $\mathrm{CS}_{2}, \mathrm{SO}_{2}, \mathrm{~S}_{\mathrm{n}}$ ) in the tail gas are converted to $\mathrm{H}_{2} \mathrm{~S}$ using hydrolysis and hydrogenation and recycled back into the Claus unit. Amine-based tail-gas cleanup is also used to recover the remaining hydrogen sulfide in the tail gas.

The Modified Claus Process with Tail Gas Cleanup Unit (TGCU) is used when very high sulfur recovery is necessary, such as for sulfur plants in petroleum refineries in the U.S. The U.S. EPA regulations normally require that the incinerated effluent from refinery sulfur plants contain no more than $250 \mathrm{ppmv}$ $\mathrm{SO}_{2}$ on a dry, oxygen-free basis. This usually corresponds to an overall sulfur recovery of 99.8$99.9 \%$. The problem with any TGCU is that it usually costs as much as the whole Claus plant while it adds only about $2 \%$ in the total sulfur recovery. Lagas, et al. ${ }^{[14]}$ describe a selective oxidation process, in which the tail gas is selectively oxidized in the presence of active metal oxides to produce sulfur

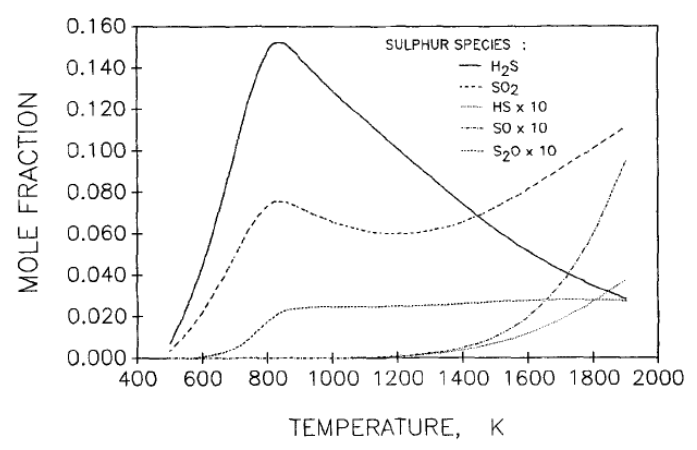

Fig. 8: Calculated concentrations of sulfur species as a function of temperature ${ }^{[16]}$

and small quantities of $\mathrm{SO}_{2}$. Total sulfur recovery of 99\% has been achieved this way $(99.4 \%$ with an additional hydrogenation step).

Oxygen enrichment technologies have been proposed to increase sulfur recovery, throughput of the system and decrease the size of the unit by reducing the amount of inert nitrogen from the process ${ }^{[15,16]}$. The resultant high flame temperatures have to be dealt with using techniques such as staged combustion and water spraying because of material limitations. The increased complexity of the system is offset by the fact that better mixing, higher reaction rates, conversion and throughput for a given size of the unit are achieved.

Figure 6 suggests that it is desirable to remove water from the reaction furnace during the process. As water is one of the products of the reaction, its removal will lead to the shift in equilibrium towards the product side and hence more conversion is achieved.

The removal of nitrogen and introduction of oxygen into the process has many effects. First, removal of the diluent nitrogen results in the increased partial pressure of each of the reacting species; second, the reduced volume of reacting gases is easier to mix; and, third, higher temperatures can be obtained. All three increases in the process rate (Fig. 8).

The use of a gas recycling process has been proposed by the CNG group ${ }^{[17]}$. The effluent gas from the first condenser was recycled back into the burner to attain overall sulfur recovery of $100 \%$. However, intermediate stages had to be used to remove water vapor and nitrogen from the recycled gas to achieve efficient conversion and stable flame regime. A separator membrane can typically be used to separate nitrogen out of the stream. However, if pure oxygen is used in the combustion process, the membrane is not necessary and only water condensation is needed before the tail gas can be recycled back into the unit. 
Am. J. Environ. Sci., 4 (5): 502-511, 2008

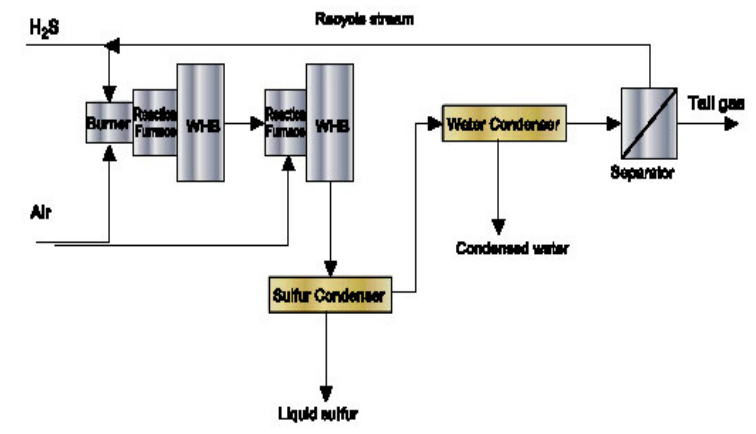

Fig. 9: Claus process with recycling ${ }^{[18]}$

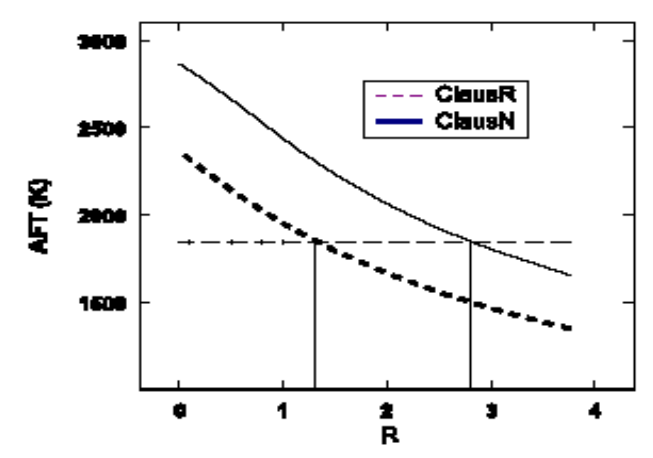

Fig. 10: Adiabatic flame temperature calculation with and without tail gas recycling as a function of $\mathrm{N} 2 / \mathrm{O} 2$ ratio $^{[18]}$

The heat recovery for this process is increased, since the water condensation heat can also be extracted out of the stream. In a recent work, El-Bishtawi, et $a l .{ }^{[18]}$ described a Claus recycle with double combustion process (Fig. 9). The acid gas was partially combusted in the first furnace and the hot exhaust was passed into the second furnace where the remainder of oxygen was added to complete the reaction. The second furnace operated at a high temperature air combustion regime, since the inlet gas was above its auto-ignition temperature.

One sulfur condenser was used following the two furnaces. Part of the effluent gas was recycled back into the first furnace. It was reported that $100 \%$ conversion could be achieved without the use of catalytic reactors and with only one condenser. Such an arrangement should reduce the cost and complexity of the system by removing the catalytic stages. It was also found that the oxygen content should not exceed $78 \%$ in order not to exceed the maximum temperature limitations of the equipment materials.

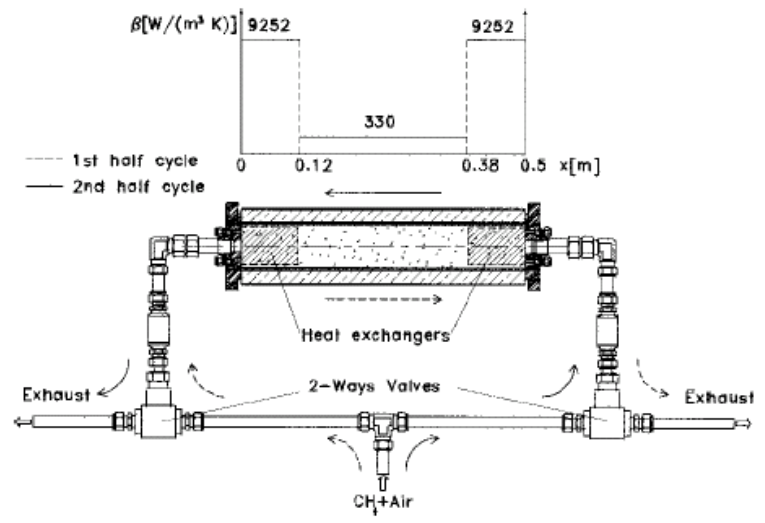

Fig. 11: Schematic of the reciprocal flow burner ${ }^{[20]}$

Claus Process with HiTAC: In the case of lean acid gas feeds $\left(<15 \% \mathrm{H}_{2} \mathrm{~S}\right)$ special considerations have to be taken in order to maintain a stable flame in the burner and achieve good combustion efficiency. Common approaches include: oxygen enrichment, a split-flow process and use of auxiliary fuel ${ }^{[15]}$. In the case of oxygen enrichment the flame temperature is increased by removing part or all of inert nitrogen from air, thus decreasing the thermal loading of the system. In the split-flow process part of the acid gas is allowed to bypass the burner, which leaves adequate fuel/air proportions in the burner and higher flame temperature. The by-pass flow is then reintroduced into the furnace at a later stage in order to keep the $\mathrm{H}_{2} \mathrm{~S}: \mathrm{SO}_{2}$ ratio 2:1 (Eq. 2 and 3). With the use of auxiliary fuel the calorific value of the gas is increased. Stable flame of a higher temperature is therefore possible.

Paskall $^{[19]}$ collected a substantial amount of field data and reviewed the literature data on sulfur conversion in Claus furnaces and recommended that sulfur conversions are greater in furnaces that are designed for greater gas mixing and turbulence and equipped with burners that provide for good mixing of the feed gas and oxidizer and in furnaces of smaller volume. HiTAC or Flameless or colorless combustion furnaces can achieve all of these recommendations and beyond, providing the highest sulfur recovery. Furthermore, Khudenko et $a l .{ }^{[10]}$ through several thermodynamic and process simulation scenarios showed that a dual thermal stage system with cold products recycle (very similar to flameless concept) provides the greatest capacity reserve. They claimed that, with the dual stage system, no changes in the existing process train are required, even when the throughput capacity of the existing conventional system is more than doubled. 


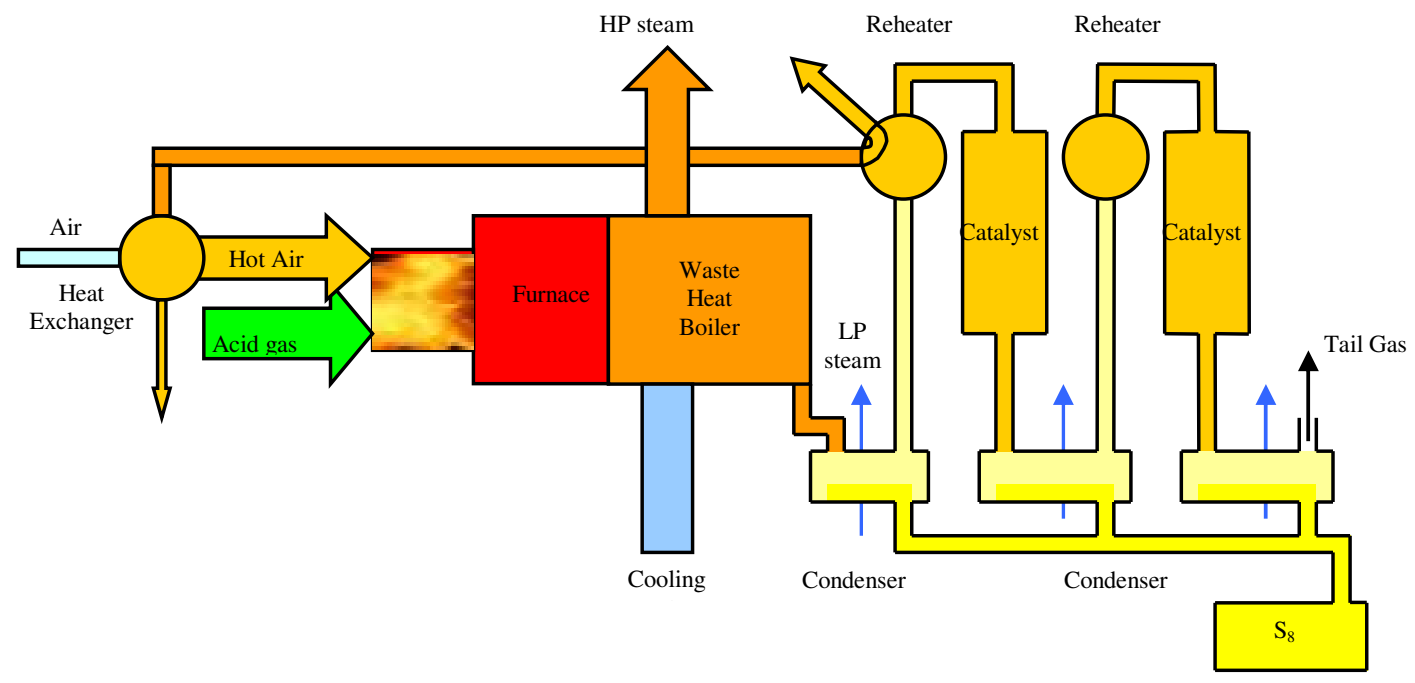

Fig. 12: Proposed Claus System With High Temperature Air Combustion

Economically this is very wise and attractive for increasing sour gas production in the oil and gas industry due to the exploitation of aging reservoirs. A reciprocal flow filtration combustor with embedded heat exchangers for super-adiabatic combustion has been proposed and studied by the Gas Technology Institute (GTI) and the University of Illinois at Chicago $^{[20]}$ (Fig. 11). The motion of the flame zone to the downstream of the reactant gas mixture results in positive enthalpy flux to the cold gas and thus increasing the reactant temperature prior to combustion. This is similar to the principles of HiTAC. A prototype was build and tested for sulfur recovery at GTI. The results showed that the super-adiabatic combustion (which is very similar to flameless or colorless combustion in principle, but taking place in a noncatalytic porous medium) significantly extends conventional flammability limits to the region of the ultra-low heat content mixtures (such as lean acid gas) and features ultra low emissions for $\mathrm{NO}_{\mathrm{x}}$ and $\mathrm{CO}$.

Therefore High Temperature Air Combustion (HiTAC) technology is proposed here as an alternative treatment of lean to very lean $\left(<15 \% \quad \mathrm{H}_{2} \mathrm{~S}\right)$ Low Calorific Value (LCV) acid gases. While a stable conventional flame is usually not achievable in this regime, HiTAC provides very lean homogeneous thermal field uniformity flames ${ }^{[5,21-24]}$. Moreover, uniform thermal characteristics with high and uniform heat flux distribution in the combustion chamber are achievable. This produces good overall conversion, low emissions and uniform heat loading of the equipment, which reduces mechanical stresses.
In fact, it has been reported that HiTAC technology has shown significant reduction in pollutants emissions (about 50\%), reduction in the size of the combustion chamber (about 25\%), reduced thermal losses to the environment and significant energy savings (about $30 \%)^{[5,23,24]}$. High temperature air combustion is especially useful for reducing $\mathrm{NO}_{\mathrm{x}}$ emissions due to its uniform thermal field and overall lower operating temperature and no adiabatic flame with hot spots that are responsible for thermal $\mathrm{NO}_{\mathrm{x}}$ formation. With the use of HiTAC the need for by-pass feed stream, oxygen enrichment and multiple furnaces could be eliminated as the lean acid gas could be oxidized in a single furnace operating above the auto-ignition temperature, with good conversion.

As far as practical considerations are concerned, the Claus process is well suited for the use of HiTAC technology, as steam generated in the waste heat boiler as well as the condensers is readily available to preheat the incoming air stream in a heat exchanger, (Fig. 12). In High Temperature Air Combustion, the air is brought to above the auto-ignition temperature of the fuel to obtain uniform ignition and combustion characteristics across the reactor. The reported auto-ignition temperature of hydrogen sulfide $\left(563 \mathrm{~K}\right.$ or $\left.290^{\circ} \mathrm{C}\right)$ is lower than a typical auto-ignition temperature for hydrocarbon fuels $\left(400-600{ }^{\circ} \mathrm{C}\right)$ and therefore requires less energy extraction from the high-pressure steam to achieve ignition and sustained combustion ${ }^{[17]}$. During the transient start-up period, preheating with an electrical heater or auxiliary fuel can be used after which self-sustained operation at steady-state 
conditions can be maintained. Issues of air/fuel mixing, flame characteristics, such as temperature, size and flammability limits, that are relevant for the Claus process, must first be investigated. The resultant uniform thermal field in the flameless combustor plus gas recycling is expected to produce close to $100 \%$ conversion.

For rich acid gas oxidation, flammability limits and flame stability are not an issue due to the high calorific value of the gas. However, thermal field uniformity offered by flameless or colorless combustion would always promote better conversion and lower pollutant emissions, among other benefits as mentioned above. Furthermore the super-adiabatic flame studies, discussed earlier, featured that fuel rich (much more than stoichiometric $\mathrm{H}_{2} \mathrm{~S}$ to oxygen ratio) conditions promote $\mathrm{H}_{2} \mathrm{~S}$ conversion to $\mathrm{H}_{2}$ and $\mathrm{S}_{2}$ rather than $\mathrm{H}_{2} \mathrm{O}$ and $\mathrm{SO}_{2}$. Their numerical results showed that at a super-adiabatic temperature of about $1650 \mathrm{~K}$ and an equivalence ratio of about 10 , an overall $\mathrm{H}_{2} \mathrm{~S}$ conversion of $50 \%$ resulted with an $\mathrm{H}_{2} / \mathrm{H}_{2} \mathrm{O}$ selectivity of $57 / 43$ and an $\mathrm{S}_{2} / \mathrm{SO}_{2}$ selectivity of $99 / 1$. These conditions, with even higher temperature, would be easily attained under flameless combustion with $\mathrm{H}_{2} \mathrm{~S}$ recycling and pre-heating. This flameless combustion assisted-thermal decomposition of $\mathrm{H}_{2} \mathrm{~S}$ would then eliminate any catalytic stage use and produce hydrogen which is highly needed in fuel processing and power production.

Of course thermal decomposition of $\mathrm{H}_{2} \mathrm{~S}$ is a well researched route for the production of hydrogen and Cox et al. ${ }^{[25]}$ presented a study on the economics of thermal dissociation of $\mathrm{H}_{2} \mathrm{~S}$ to produce hydrogen and some studies are even at the pilot plant stage. However, none of the early studies address the problem of heat transfer. Due to the endothermic heat of reaction, heat transfer limits the overall rate of reaction resulting in low conversions. However, with flameless or colorless combustion the $\mathrm{H}_{2} \mathrm{~S}$ rich mixture reacts in a very hot homogeneous medium with no heat transfer limitations and therefore will present much higher conversions.

\section{CONCLUSION}

A review of the sulfur recovery process from acid gases has been presented. The conventional modified Claus process and its derivatives have been presented and discussed. It is shown that all improvements towards very high sulfur recovery induce very high cost additions to an already economically deficient process. HiTAC has been shown to feature great potential for an almost complete sulfur recovery from lean acid gases.
The flameless or colorless combustion has been proposed to be a very promising process for sulfur recovery and hydrogen production from rich acid gases. Therefore, these last two technologies feature the potential for reducing the complexity and the cost of the sulfur recovery process.

\section{REFERENCES}

1. Converting Hydrogen Sulfide by the Claus Process. http://www.nelliott.demon.co.uk/company/claus.ht $\underline{\mathrm{ml}}$

2. Wünning, J.A. and J.G. Wünning, 1997. Flameless oxidation to reduce thermal NO formation. Prog. Energy Combust. Sci., 23: 81-94.

3. Katsuki, M. and T. Hasegawa, 1998. The science and technology of combustion in highly preheated air. The 27th Symposium (International) on Combustion, pp: 3135-46.

4. Gupta, A.K. and Z. Li, 1997. Effect of fuel property on the structure of highly preheated air flames. ASME International Joint Power Generation Conference, Denver CO, ASME EC, 5: 247-57.

5. Tsuji, H., A.K. Gupta, T. Hasegawa, K. Katsuki, K. Kishimoto and M. Morita, 2003. High Temperature Air Combustion: From Energy Conservation to Pollution Reduction, CRC Press, pp: 401.

6. Elsner, M.P., M. Menge, C. Müller and C.W. Agar, 2003. The Claus process: teaching an old dog new tricks, Catalysis Today, 79-80: 487-94.

7. Monnery, W.D., W.V. Svrcek and L.A. Bhie, 1993. Modelling the modified Claus process and the implications on plant design and recovery. Can. J. Chem. Eng., 71: 711-24.

8. Sulfur Production Report, 2006. United States Geological Survey http://en. wikipedia. org/wiki/ Amine_gas_treating

9. Khudenko, B.M., G.M. Gitman and T.E.P. Wechsler, 1993. Oxygen based Claus process for recovery of sulfur from $\mathrm{H}_{2} \mathrm{~S}$ gases. J. Environ. Eng., pp: 1233-51.

10. Converting Hydrogen Sulfide by the Claus Process. http://www.nelliott.demon.co.uk/company/claus.ht $\underline{\mathrm{ml}}$

11. Cold Bed Adsorption Process. http://www.ortloff.com/sulfur/cba.htm

12. Modified Claus Process With Tail Gas Cleanup. http://www.ortloff.com/sulfur/claus-tailgas.htm

13. Lagas, J.A., J. Borsboom and G. Heijkoop, 1989. Claus process gets extra boost, Hydrocarbon Processing, pp: 40-42. 
14. Goar, B.G., W.P. Hegarly, R. Davis and R. Kammiller, 1985. Claus plant capacity boosted by oxygen enrichment process. Tech., Oil and Gas J., pp: 39-41.

15. Khudenko, B.M., G.M. Gitman and T.E.P. Wechsler, 1993. Oxygen based Claus process for recovery of sulfur from $\mathrm{H}_{2} \mathrm{~S}$ gases. J. Environ. Eng., pp: 1233-51.

16. Klint, B.W., P.R. Dale and C. Stephenson, 1997. Low quality natural gas sulfur removal and recovery, CNG Claus sulfur recovery process, pilot plant test program-bovar for CNG Research, Proceedings of the Natural Gas Conference, Emerging Technologies for the Natural Gas Industry, Federal Energy Technology Center (FETC), Houston, Texas.

17. El-Bishtawi, R. and N. Haimour, 2004. Claus recycle with double combustion process. Fuel Processing Technology, 86: 245-60.

18. Paskall, H.G., 1979. Capability of the modified Claus process. Western Research, Alberta, Canada.

19. Fabiano C., W.M. Barcellos, A.V. Saveliev and A.L. Kennedy, 2005. Energy extraction from a porous media reciprocal flow burner with embedded heat exchangers. J. Heat Transfer, 127(2): 123-30.
20. Mortberg, M., W. Blasiak and A.K. Gupta, 2006. Combustion of low calorific value fuels in high temperature and oxygen deficient environment. Combustion Sci. and Tech. (CST), pp: 1345-72.

21. Bolz, S. and A.K. Gupta, 1998. Effect of air preheat temperature and oxygen concentration on flame structure and emissions. Proc. Intl. Joint Power Joint Generation Conference (IJPGC98), Baltimore, MD, ASME FACT, 22: 193-205.

22. Gupta, A.K., 2004. Thermal characteristics of gaseous fuel flames using High Temperature Air. ASME J. Eng. Gas Turbine and Power, 126(1): 9-19.

23. Hasegawa, T., S. Mochida and A.K. Gupta, 2002. Development of advanced industrial furnace using highly preheated air combustion. J. Propulsion and Power, 18(2): 233-39.

24. Cox, B.G., P.F. Clarke and B.B. Pruden, 1998. Economics of thermal dissociations of $\mathrm{H} 2 \mathrm{~S}$ to produce hydrogen. Int. J. Hydrogen Energy, 23(7): 531-44. 